\title{
Introduction to the Special Issue on Tone at the Top
}

\author{
Sally Gunz $\cdot$ Linda Thorne
}

Published online: 28 January 2014

(C) Springer Science+Business Media Dordrecht 2014

In 1987, the Treadway Commission Report presented its key recommendations and introduced the expression "Tone at the Top" to the ethics, governance, and accounting literatures. In May of 2013, the University of Waterloo Centre for Accounting Ethics sponsored a Symposium for leading accounting ethics scholars, dedicated to this theme, and this Special Issue is the culmination of that event.

Tone at the Top describes the "ethical atmosphere that is created in the workplace by the organization's leadership. Whatever tone management sets will have a trickledown effect on employees of the company." ${ }^{1}$ The Treadway Commission (chaired by James Treadway), sponsored and funded by five US accounting associations to develop guidance on fraudulent reporting and internal control, identified Tone at the Top as one of the key factors in preventing and/or identifying fraud within an organization. The first accounting academic paper examining the importance of Tone at the Top to accounting, and more specifically audit firms, was published soon after in the Journal of Business Ethics. It is now 25 years since this article, "Ethical Problems in Public Accounting: the View from the top" by Don Finn and his two coauthors, marketing researchers, Lawrence Chonko and Shelby Hunt, first appeared. This research identified the critical role of audit partners in establishing the ethical culture of audit firms. The interest and importance of this topic has

\footnotetext{
S. Gunz $(\bowtie)$

School of Accounting and Finance, University of Waterloo, Waterloo, ON, Canada

e-mail: sgunz@uwaterloo.ca

L. Thorne

Schulich School of Business, York University, Toronto, ON, Canada

e-mail: 1thorne@schulich.yorku.ca
}

continued. It is a fitting tribute to Don Finn's pioneering work that his work as a Discussant appears in this Special Issue.

If a rough and an unscientific evaluation of the degree of interest in a topic can be estimated by the number of "hits" in ABI Inform and Google, then the importance of the phrase "Tone at the Top" is measured by 7982 hits in ABI Inform and 2.26 million hits in Google in November 2013. As well as reflecting the continued interest in Tone at the Top by the general public, the business world and academe, our Symposium demonstrates the breadth to which the concept of Tone at the Top has been applied by academic researchers. The original focus was upon how the audit manager's ethical tone influenced the ethical culture and actions of employees throughout audit firms. Today, the application of Tone at the Top has been extended to all types of firms, and extends to considerations of factors that might reinforce or mitigate the influence of Tone at the Top on ethical culture. More recently, investigations have considered how to ameliorate Tone at the Top through regulatory, compensatory, and social encouragements. Finally, all times of research methodologies have been now applied to these important questions.

In his keynote address at the Tone at the Top Symposium, Chris Macdonald (The Business Ethics Blog, 2013, $04 / 19 /$ does the right tone at the top guarantee success) identified two "unavoidable truths" about ethical leadership and the Tone at the Top: (1) ethical tone must be established at the top of the organization and communicated downward throughout the organization, and (2) ethics cannot be simply imposed by the organization; it must be

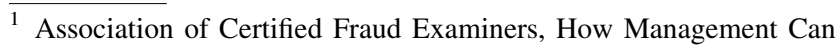
Prevent Fraud in the Workplace, http://www.acfe.com/uploadedFiles/ ACFE_Website/Content/documents/tone-at-the-top-research.pdf.
} 
reinforced by the practices, systems, structures, and ultimately the actions espoused throughout the organization.

Much of the early research on Tone at the Top focused on the first "unavoidable truth" by examining how the establishment of codes of conduct, ethical training, and other factors can positively influence ethical climate and behavior. This Special Issue includes eight papers that extend our knowledge on both the first and second of the "unavoidable truths" presented by Chris Macdonald. Three papers focus on the first "unavoidable truth" by increasing our understanding of the effect of the ethical Tone at the Top (Kaplan, Samuels and Cohen; Lail, MacGregor, and Stuebs, and Thomasson; Bozzolan, Cho and Michelon). Lail et al. examine the importance of Tone at the Top in insuring the effectiveness of regulation for financial and tax reporting. Using an experimental methodology, Kaplan et al. show that employees' perceptions of CEO reputation were impacted by social ties with the compensation committee and quality of financial reporting disclosures. Using a case study of Fiat Group, Bozzolan et al. demonstrate the importance of Tone at the Top for addressing stakeholder interactions and concerns.

Five papers focus on the second "unavoidable truth" by investigating which practices, systems, and structures can strengthen the link between ethical tone and ethical actions throughout the organization (i.e., Shapiro and Naughton; Shafer; Gao, Greenberg, and Wong-on-Wing; Patelli and Pedrini; Bobek, Hageman and Radtke). Using a case study methodology, Shapiro and Naughton demonstrate the linkages between a company's culture, including espoused values, organizational practices, and financial management. Using a survey of professional accountants, Shafer shows that perceptions of ethical climate are associated with intentions for ethical financial reporting. Using an experimental methodology, Gao et al. demonstrate the importance of an externally administered reporting channel for encouraging whistle-blowing intentions. Patelli and Pedrini demonstrate the relationship between aggressive financial reporting and the Tone of Top as captured in annual letters to shareholders. Using a survey methodology, Bobek et al. show that the importance of audit partners' perceptions of their role in influencing their organizations' ethical environment is critical to influencing the ethical culture of the firm.

This Special Issue not only includes research extending our understanding of both "unavoidable truths" but also reflects the breadth of context to which Tone at the Top research has been applied, as well as a range of research perspectives and methods. This collection of research papers reinforces the importance of the Tone of the Top in influencing organizations' ethical practices and culture. It also suggests important ways and factors that affect the Tone at the Top. Finally, we incorporate, in this Special Issue, 6 comments from Discussants of papers presented at the Symposium. Each not only expands upon the ideas presented by the respective authors but also presents thoughtful assessments of where research may lead in the future. While significant inroads have been made into understanding Tone at the Top, much more work remains to be done.

\section{References}

Association of Certified Fraud Examiners. How Management Can Prevent Fraud in the Workplace. http://www.acfe.com/uploaded Files/ACFE_Website/Content/documents/tone-at-the-top-research. pdf. Retrieved 6 Jan 2014.

Chris Macdonald (The Business Ethics Blog, 2013, 04/19). Does the Right Tone at the Top Guarantee Success. http://www.canadian business.com/blogs-and-comment/does-the-right-tone-at-the-topguarantee-success/. Retrieved 6 Jan 2014.

Finn, D., Chonko, L., \& Hunt, S. (1988). Ethical problems in public accounting: The view from the top. Journal of Business Ethics, 7, 605-615.

Report of the National Commission on Fraudulent Financial Reporting (Treadway Commission Report), October, (1987).www.coso. org/publications/ncffr.pdf. Retrieved 6 Jan 2014. 